\title{
Adapting Darnton's Nine Principles Framework for Behaviour Change: The UK Upcycling Case Study
}

\author{
Kyungeun Sung $1, * \mathbb{D}$, Tim Cooper $^{2}\left(\mathbb{D}\right.$ and Sarah Kettley ${ }^{3}$ \\ 1 School of Art, Design and Architecture, De Montfort University, Leicester LE1 9BH, UK \\ 2 School of Architecture, Design and the Built Environment, Nottingham Trent University, \\ Nottingham NG1 4FQ, UK; t.h.cooper@ntu.ac.uk \\ 3 School of Design, The University of Edinburgh, Edinburgh EH1 2LE, UK; sarah.kettley@ed.ac.uk \\ * Correspondence: Kyungeun.sung@dmu.ac.uk; Tel.: +44-0116-2078-8498
}

Citation: Sung, K.; Cooper, T.; Kettley, S. Adapting Darnton's Nine Principles Framework for Behaviour Change: The UK Upcycling Case Study. Sustainability 2022, 14, 1919. https://doi.org/10.3390/su14031919 Academic Editor: Adriana Del Borghi

Received: 31 December 2021

Accepted: 1 February 2022

Published: 8 February 2022

Publisher's Note: MDPI stays neutral with regard to jurisdictional claims in published maps and institutional affiliations.

Copyright: () 2022 by the authors. Licensee MDPI, Basel, Switzerland. This article is an open access article distributed under the terms and conditions of the Creative Commons Attribution (CC BY) license (https:// creativecommons.org/licenses/by/ $4.0 /)$.

\begin{abstract}
Design practitioners and academics have increasingly recognised the potential value of design for behaviour change. On the one hand, while existing studies address product or communication design as main interventions, there is a growing interest in design as a useful tool for policy development and service innovation. On the other hand, the interplay between social research, design, and policy development in behaviour intervention is not a new concept or practice, yet studies to suggest and evaluate particular general approaches to policy and design interventions are relatively new and rare. To fill this knowledge gap, this paper adapts Darnton's Nine Principles framework as one promising generic approach, demonstrates how the adapted framework can be applied to the upcycling case study in the UK and evaluates the usefulness of the adapted framework. The study results show that the adapted framework is useful for exploring behaviour and developing interventions in small-scale, exploratory studies, and that it can be applied to other behaviour domains and contexts. The main contribution of this paper is the demonstration of the potential of Darnton's original and adapted frameworks as a promising general approach useful for policy and design interventions.
\end{abstract}

Keywords: behaviour change; Darnton's Nine Principles framework; design; intervention; policy; scaling-up; sustainability; upcycling

\section{Introduction}

Design practitioners and academics are increasingly aware that influencing human behaviour is a new role for design aimed especially at environmental or social benefits beyond the more traditional role of meeting consumers' needs and wishes through the design of products and services [1-5]. This new 'design for behaviour change' practice has been utilised in the areas of sustainability, health, safety, crime prevention and many more areas [5]. In these applications, different design approaches to influencing behaviour (i.e., reinforcing desirable behaviours or changing undesirable ones) have been explored. For instance, Clune [2] used the four stages of community-based social marketing [6] for design interventions aimed at behaviour change. Lilley [3] studied the approaches led by design for influencing user behaviour to lessen adverse social impacts by product use and suggested a conceptual framework to design devices for behaviour change. Tang [7] created a design behaviour intervention model to link the theories of social psychology with design approaches to behaviour intervention to encourage more sustainable behaviour for lowering environmental impacts at the household level. Lockton et al. [8] suggested a design with intent method which is an innovation tool for product designers and system developers to affect user behaviour for reducing user errors and improving performance. Dorrestijn [9] developed a product impact tool for product developers, reflecting varied modes of interaction (e.g., abstract, cognitive, environmental and physical). Niedderer [5] 
recommended mindful design as a way of creating lasting behaviour change which puts mindfulness at the core of design practice [10] as an open attitude for an increased level of awareness of, reflection on, and responsibility in design.

Most of the aforementioned approaches have suggested (or assumed) either product or communication design (graphics and information) as a form of intervention. The forms of intervention outside this remit, such as service design, are largely missing, which is an important knowledge gap. At the same time, design has been increasingly viewed as a useful tool for policy development and service innovation for the public sector based on social research [11-14]. The interplay between social research, design and policy development in behaviour intervention is not a new concept or practice, yet studies to suggest and evaluate particular general approaches to policy and design interventions are relatively new and rare. To fill this knowledge gap, this paper introduces Darnton's Nine Principles framework [15] as one of the promising generic approaches, adapts it and evaluates the usefulness of the adapted framework. The essence of Darnton's framework is that it integrates behaviour models as underpinning theoretical frameworks in the process for behaviour change (or influencing behaviour). As every framework is neither perfect nor perfectly suitable for all cases, Darnton's framework may have limitations which require a certain level of adaptation. We should note here that researchers' need for modifying frameworks is not unusual. They do so to ensure that the frameworks are more suitable for their particular study cases.

To clarify, this paper is not positioned to provide detailed empirical research outcomes in terms of what new data was discovered or what intervention was designed and developed. The focus of this paper is to introduce and review Darnton's framework, using the case study in terms of showing how the framework could be adapted and applied as well as how useful the framework is as a general approach to design and policy intervention projects. This paper is going to: (i) give a critical review of Darnton's framework including its limitations (Section 1.1); (ii) describe the upcycling case study (Section 1.2); (iii) explain the methods (research question, hypotheses and research activities) (Section 2); (iv) suggest an adapted framework which is more suitable for a small-scale, exploratory study with step-by-step application of the adapted framework to the case study (Section 3); (v) discuss each step of each stage of the adapted framework in the case study and provide suggestions for future research (Section 4); and (vi) conclude that the adapted framework is suitable for use in small-scale exploratory studies and describe the contribution to the knowledge (Section 5).

\subsection{Darnton's Nine Principles Framework and Its Limitations}

Scientists and policy makers often assume that understanding behaviour (and specifically policies to change behaviour) requires behaviour models that explain factors and/or conditions affecting particular behaviours [16]. Darnton's Nine Principles framework provides a starting point for selecting appropriate behaviour models and developing interventions to influence behaviours [15]. It offers useful guidance based on valid and reliable theories for planning and developing interventions in a similar way to 'community-based social marketing' (emphasising direct contact with community members to identify barriers to a behaviour, develop and pilot a programme, and implement and evaluate the programme) [6] and 'Stern's principles' for intervention design aimed to change environmentally damaging behaviour (e.g., understand the actor's situation, apply theories to understand and affect human choice processes, consider conditions beyond individuals, monitor responses and continuously improve programmes accordingly) [17]. The distinctiveness in Darnton's framework, however, is that it emphasises the importance of the establishment and use of appropriate behaviour models in the process of developing interventions [15]. Darnton's framework was developed in the UK's Government Social Research to improve the conceptualisation and measurement of fundamental concepts by government social researchers to facilitate the use of social research in policy development and evaluation as well as in measurement of long-term trends. The framework is based on 
the review of more than 60 behaviour models and theories in social psychology. We believe that this framework is a credible and valid reference.

The nine principles in Darnton's framework are: (i) identify target people (audience or actors) and behaviour; (ii) identify pertinent behaviour models and extract a shortlist of factors influencing the target behaviour; (iii) select key influencing factors and use them to define objectives in draft strategies for interventions; (iv) identify effective interventions; (v) engage target audiences for the interventions; (vi) develop prototype interventions; (vii) pilot the interventions and monitor outcomes continuously; (viii) evaluate the processes, outcomes and impacts of the interventions; and (ix) feed learning from the evaluation back into the process (Figure 1).

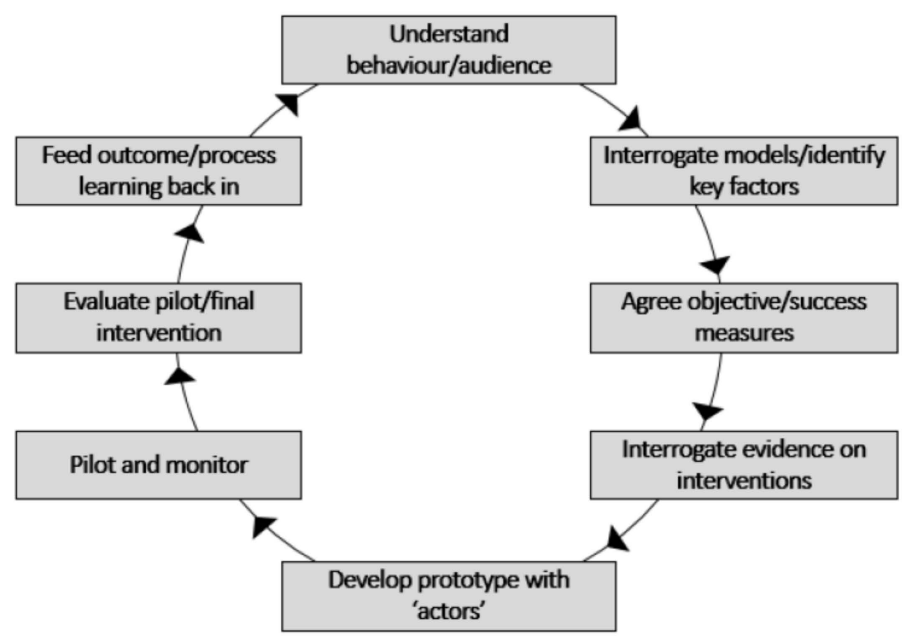

Figure 1. Darnton's Nine Principles framework, combining (v) and (vi) (see above) as ‘Develop prototype with 'actors".

Darnton made a number of assumptions in his framework. First, identifying target audience and behaviour is sufficient for the stage of understanding behaviour and audiences. This excludes the cases addressing an emergent behaviour/phenomenon where new empirical research is required due to a lack of past investigations into the emerging behaviour (e.g., upcycling behaviour). Second, extracting the key factors influencing behaviour from existing behaviour models and past empirical studies is appropriate and valid in all cases. This may not be the case all the time, especially when addressing emerging behaviours with limited previous studies. Third, co-creating and piloting intervention prototypes with the target audience is a prerequisite for developing effective interventions. This limits the cases where there are insufficient resources available (e.g., financial support and time for prototyping, piloting, continuous monitoring and adjustment accordingly). Adaptation of Darnton's framework can address these aforementioned issues, and this paper mainly illustrates the adapted framework using the upcycling case study that required new empirical research and had limited resources for prototyping, piloting, etc.

\subsection{The Upcycling Case Study: Scaling-Up Upcycling with an Ultimate Goal of Reducing Carbon Emissions}

Upcycling is a collective term (or umbrella concept) to describe all sorts of 'creative' processes through which a product or an artefact is created or modified from used (or waste) products, components or materials, with higher (or equal) value or quality than the original elements $[18,19]$. Practices such as 'creative' or 'innovative' forms of repair, reuse, repurposing, refurbishment and remanufacturing that would exist in a 'circular economy' - an alternative to the traditional and current linear system based on resource extraction, production, use and disposal [20,21] — may enable value to be retained and thus constitute upcycling. 
In principle, upcycling extends the lifetimes of products, materials and components, reduces solid waste, increases material efficiency and reduces energy consumption, contributing ultimately to the reduction of greenhouse gas (GHG) emissions [19,22,23]. Companies that upcycle can be financially viable and create new job opportunities, both in theory and practice [24-26]. In households, individual 'upcyclers' obtain psychological and sociocultural benefits such as empowerment, relaxation and a sense of belonging [18,19]. Despite such potential benefits, however, upcycling is a niche behaviour currently and 'scaling it up'-transitioning upcycling from niche to mainstream [27] — could have a meaningful impact on the environment, society and people $[19,26,28]$.

To this end, this study investigated upcycling, focusing on UK households, with the aim of developing promising interventions for scaling-up upcycling, whether in households or large-scale businesses in the UK. This research was conducted within the Centre for Industrial Energy, Materials and Products (CIE-MAP) which was established to identify opportunities to deliver reductions in the use of materials and energy consumption [29]. CIE-MAP was one of six centres under End Use Energy Demand [30] founded by UKRI (UK Research and Innovation) as part of the UK Government's commitment to achieving its target to cut carbon emissions by at least 80\% from 1990 levels by 2050 [31].

\section{Methods}

This section describes the research question, hypotheses and research activities. The key research question was: 'Is Darnton's Nine Principles framework useful as a general approach to policy and design interventions'? The hypotheses were as follows: (H1) If Darnton's Nine Principles framework is critically reviewed, its limitations will be uncovered; (H2) If Darnton's Nine Principles framework is adapted (assuming H1 is correct), the adapted framework will be applicable to the case study; and (H3) If the adapted Darnton's framework is applied to the case study, the results will show the usefulness of the adapted framework for policy and design intervention. The research activities were therefore: first, literature review to understand Darnton's Nine Principles framework and identify its limitations (for H1); second, adaptation of the Darnton's framework and its application to the case study (for H2) utilising mixed methods (interviews, survey, and modified Delphi method $[19,28]$ ); and third, critical reflection on the case study (for H3). In the case study, semi-structured interviews with 23 UK citizens with practical upcycling experience were conducted (Section 3.1.1. Step Two: Understand consumer behaviour)). An online survey with 122 UK citizens with upcycling experience was conducted (Section 3.2.2. Step Four: Identify key drivers, facilitators and barriers). Twenty-five UK experts participated in the questionnaire and workshop studies as part of modified Delphi (Section 3.3.2. Step Six: Evaluate and improve the draft interventions).

\section{Adaptation of Darnton's Nine Principles Framework and Its Application}

This section illustrates the stages and steps in the adapted framework of Darnton's Nine Principles framework [15], which focuses on the early phases of behaviour intervention: investigation into the target behaviour and generation of intervention ideas. The adaptation made to these early phases was to understand relatively underexplored behaviour and identify key factors influencing the behaviour based on empirical research, and propose promising interventions without prototyping with the target audience and piloting under limited resources. We are not suggesting that it is unnecessary to prototype or pilot the interventions. Instead, we suggest how the cycle or the long process can be divided into two parts for interim decision making and planning (i.e., early phases for behaviour investigation and intervention generation, and later phases for prototyping, piloting, etc.). By providing prioritised intervention options at the end of the research-led intervention generation process, resources can be invested in prototyping and piloting more effectively.

The assumption we made is that a design practitioner or researcher (or other actors) knows which particular behaviour to target. We suggest three early stages and two steps 
in each stage in the adapted framework. Stage one: 'understanding consumer behaviour' includes step one, 'identify behaviour model for exploration' based on theory understanding and step two, 'understand consumer behaviour' by research. Stage two: 'identifying key factors influencing behaviour' includes step three, 'refine the behaviour model for operationalisation' based on further literature review and step four, 'identify key drivers, facilitators and barriers' by research. Stage three: 'developing interventions' includes step five, 'design promising interventions' by design and step six, 'evaluate and improve the draft interventions' by research (Figure 2). The following subsections describe each of these steps and illustrate how each step was addressed in the upcycling case study.

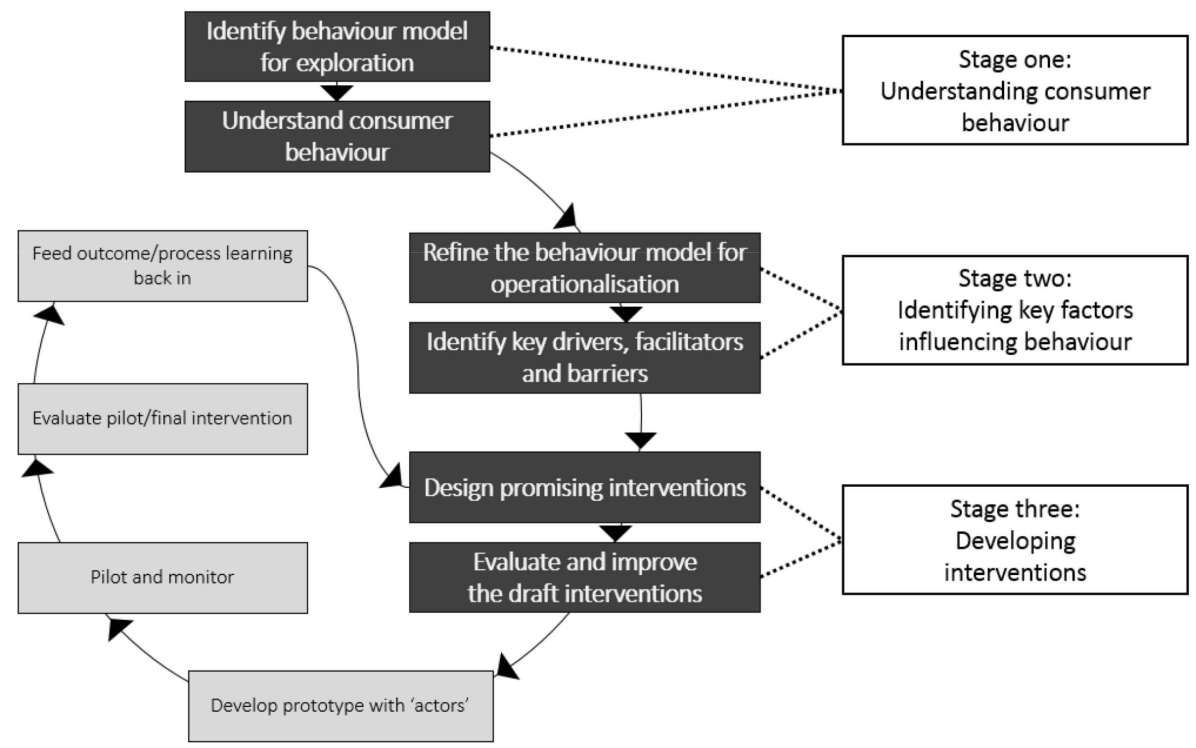

Figure 2. Adapted framework from Darnton's Nine Principles framework: dark grey textboxes represent the adapted processes of research and design, and light grey textboxes show part of the original framework.

\subsection{Stage One: Understanding Consumer Behaviour}

\subsubsection{Step One: Identify Behaviour Model for Exploration}

A crucial first step is to identify an appropriate behaviour model for exploring the targeted behaviour by secondary research including literature review, since different factors and their combinations drive or influence different behaviours [15]. The number of factors used in a particular behaviour model determines the scope of understanding. When a researcher attempts to investigate a certain behaviour for interventions without appropriate expertise (such as psychology), deciding on the right model may be challenging. In this case, Darnton's 'practical guide' to behaviour models [15] can be helpful. It provides a matching table to show which behaviour models are suitable for which behaviour domains such as health, consumption, environment, community participation, work and savings, transport, addictive behaviour and others. In the upcycling case study, conducting a thorough, comprehensive literature review was the first step, which resulted in the conclusion that Triandis's theory of interpersonal behaviour [32] was the most suitable model for exploration. The conclusion was based on evidence from multiple studies suggesting that Triandis's model provides a good synthesis and a reasonable starting point for understanding any sustainable behaviour [33-35]. Detailed descriptions of the theory, the rationale behind the choice and evidence are found in Sung et al. [36].

\subsubsection{Step Two: Understand Consumer Behaviour}

Although Darnton's approach includes identifying which groups of people and which behaviour to target during the stage of understanding consumer behaviour [15], exploratory approaches could be used for understanding consumers and their particular behaviour 
to gain additional insights for developing interventions. For example, researchers could investigate what kind of factors influence the behaviour, what kind of attitudes, beliefs and opinions people hold about the behaviour, the context of the behaviour, approaches to the behaviour or any other particularities regarding the behaviour using qualitative research such as interviews, focus groups, observation or a combination of these. In the upcycling case study, interviews were carried out with 23 UK consumers with practical upcycling experience. The interview schedule was based partially on influencing factors (or variables) in Triandis's theory of interpersonal behaviour such as perceived benefits of the behaviour, emotions, habits, social factors and facilitating conditions, while other questions covered the context of, and approaches to upcycling. The interviews revealed approaches to upcycling (e.g., common upcycling materials, where to source materials, selection criteria for materials), the context for upcycling (e.g., when, where, with whom the interviewees upcycled), and a variety of factors influencing upcycling (e.g., consumers perception of the benefits of upcycling, emotions involved in upcycling, barriers to and facilitators for upcycling). Detailed descriptions of the interview schedules, procedures, interviewees and results have been previously reported [19,37].

\subsection{Stage Two: Identifying Key Factors Influencing Behaviour}

3.2.1. Step Three: Refine the Behaviour Model for Operationalisation

Although Darnton's original framework suggests identifying key factors influencing behaviour through secondary research, one needs to undertake primary research when dealing with emerging behaviours with limited previous studies. In that case, to identify key influencing factors, quantitative research such as a survey can be implemented. Before conducting such quantitative research, one needs to ensure that the selected behaviour model is operationalisable for a survey. Further literature review can provide an opportunity to refine the selected model that is suitable for the target behaviour. The review process can also reveal an existing research instrument that has been tested and validated. In the upcycling case study, during the investigation some issues with the selected model (Triandis's model) became apparent. There were no clear guidelines or operational definitions for behaviour factors in the original model [38]. There were inconsistencies among the instruments when the original model was used in different studies [39-41]. In an attempt to address these issues, Triandis's theory of interpersonal behaviour was merged with Ajzen's theory of planned behaviour [42,43], one of the most widely used behavioural models, with well-defined, operationalisable factors. Detailed descriptions of the issues with the theory of interpersonal behaviour and the combination model are found in Sung et al. [36].

\subsubsection{Step Four: Identify Key Drivers, Facilitators and Barriers}

Key factors that influence the target behaviour (e.g., key drivers, facilitators and barriers) can be identified by quantitative research such as surveys utilising the selected and refined behaviour model (and also using the particular variables revealed by the qualitative research previously undertaken). To identify key factors, statistical analysis such as multiple regression analysis [44] can be used to reveal to what extent the model explains the behaviour variance and which factors have more influence. In the upcycling case study, a survey study (online) of 122 UK 'makers' [36] - embracing makers, crafters, hackers, fixers, tinkerers, gardeners, knitters and bakers [45]—was undertaken. Questions were based on the combination model (Triandis's + Ajzen's). Statistical analysis (logistic regression) revealed the key determinants of upcycling as 'intention' and 'subjective norm' (i.e., social acceptance and approval) and the key determinants of intention to upcycle as 'attitude' (i.e., perceived value of the behaviour such as good, worthy) and 'social factors' - 'personal norm' (i.e., personal values and principles), 'subjective norm' and 'role belief' (i.e., relation to personal roles in family, work, etc.). The analysis (non-parametric statistics for comparing groups) uncovered the potential target population for interventions to scale-up upcycling as women aged 30+ with occupational areas in art and design. Detailed descriptions of the 
survey questions, procedures, respondents, approaches to data analysis and statistical test results are presented in Sung et al. [36].

\subsection{Stage Three: Developing Interventions}

\subsubsection{Step Five: Design Promising Interventions}

Designing effective or promising interventions needs to be based on scientific findings and insights from the previous steps. Step five starts with synthesising such findings and insights, and identifying their implications for developing interventions. This design step can also be informed by secondary research looking at existing interventions. Darnton [15], for example, considered Abraham and Michie's [46] typology of techniques in behaviour change based on meta-analysis as a useful starting point. In the upcycling case study, Defra's (Department of Environment, Food and Rural Affairs) 4Es approach—enable, engage, encourage and exemplify [47] — was considered as another useful source for addressing sustainable behaviours [28]. In this step, while considering research outcomes and existing interventions, 'strategic design' - design of an integrated system of products, services and other measures with strategies linking goals, forming new organisations, and reconfiguring stakeholders' roles [48] — can be used in the search for promising intervention ideas. In the upcycling case study, all qualitative and quantitative research outcomes were synthesised and used as inputs for individual idea generation, resulting in a number of initial interventions. These initial interventions were mapped onto the models for behaviour intervention by Defra [49,50] and Michie et al. [51], producing 15 interventions for testing and evaluation. Detailed descriptions of the synthesis of research outcomes, idea generation, idea mapping, and a list of interventions can be found in Sung et al. [28].

\subsubsection{Step Six: Evaluate and Improve the Draft Interventions}

Evaluating and improving initial or draft intervention ideas is a vital final step that precedes the stage of developing prototypes with a target population. This step can be used for a group of experts (or stakeholders or target population) to explore and evaluate the initial interventions based on, for example, feasibility (economic, political and technical), importance (how much impact or change they could make) and desirability by the target population. They could make new suggestions (e.g., new interventions) and offer comments (e.g., how each intervention could be improved) and other feedback (e.g., concerns or issues) regarding the interventions, enabling the initial interventions to be improved. In the upcycling case study, a modified form of the Delphi method $[19,28]$ was used. Twenty-five UK experts in sustainable development, sustainable design, transition for sustainability, environmental policies, social innovation and behaviour change were asked to review initial interventions through an online questionnaire. A subgroup of these experts participated in a subsequent workshop to further the discussion of the feasibility and importance of the interventions, and how each one could be improved and implemented. This process resulted in a list of prioritised short-term and long-term interventions as well as suggestions for implementation. Detailed descriptions of the questions used in the survey, workshop schedule, procedures, discussion points, participant information, survey results, and workshop results can be found in Sung et al. [28].

\section{Discussion}

To summarise the case study: step one, 'identify behaviour model for exploration', resulted in the conclusion that Triandis's theory of interpersonal behaviour was the most suitable model for exploration; step two, 'understand consumer behaviour', using interview studies revealed some approaches to upcycling, the context for upcycling and a variety of factors influencing upcycling; step three, 'refine the behaviour model for operationalisation', merged Triandis's model with Ajzen's theory of planned behaviour model to improve operationalisation and explanation power; step four, 'identify key drivers, facilitators and barriers', using an online survey based on the combination model (Triandis's and Ajzen's) revealed the key determinants of upcycling and potential target population for 
interventions for scaling up upcycling; step five, 'design promising interventions', based on design thinking and mapping exercise produced 15 initial interventions; step six, 'evaluate and improve the draft interventions', resulted in a list of prioritised short- and long- term interventions and suggestions for implementation.

To reflect on each step, in step one, 'identify behaviour model for exploration', a thorough literature review was conducted, which offered a meaningful conclusion (advantage) yet this may not always be feasible (e.g., for policy makers and design practitioners working under severe time pressure) (disadvantage). In such cases, Triandis's theory of interpersonal behaviour can be a safe starting point, based on other experts' suggestions [33-35] and the applicability of Triandis's model to most behaviour domains (e.g., technology adoption [52], civic behaviour [53], dietary behaviour [54], sustainable product use at home [7], sustainable consumption [33] and energy-related behaviour [34]). In step two, 'understand consumer behaviour', interviews were carried out with UK consumers with practical experience of upcycling. Although the results revealed some important information about upcycling within a relatively short space of time (advantage), the findings were limited regarding upcycling processes and the skills involved (disadvantage). For future research addressing behaviour investigation and intervention development, a mixed methods approach [55] combining interviews and observation is recommended. In particular, ethnographic research [56] may prove valuable through which participants can be observed and studied in their real-life environment, providing fuller and more complete descriptions of the participants' behaviours and other relevant information (e.g., specific materials, tools, spaces used).

In step three, 'refine the behaviour model for operationalisation', Triandis's theory of interpersonal behaviour was combined with Ajzen's theory of planned behaviour. Many empirical studies using Triandis's model reveal operationalisable frameworks that are slightly different from the original model, due mostly to its ambiguities. They therefore exhibit inconsistencies in frameworks, resulting from different interpretations and unavoidable adaptations $[19,40,41,52]$. Lack of clarity in Triandis's model can be resolved by borrowing the terms and definitions from Ajzen's most widely used model, whereas the lack of explanation power in Ajzen's model can be compensated by using more of the variables used in Triandis's model [36]. This kind of expansion of the theory of planned behaviour has, indeed, been utilised in other studies [57-60], confirming the appropriateness of the approach taken in the upcycling case study (advantage). However, whether the combined model is the optimal or best one could be questioned (disadvantage). This calls for a need for further investigation of which extended theory of planned behaviour is more appropriate for which behaviour (or which extended theory is the most appropriate for most behaviour domains). Defining and providing a crystal-clear framework and guidelines for empirical research using Triandis's theory of interpersonal behaviour based on systematic literature review and comprehensive meta-analysis, would also be an invaluable future research contribution to the behaviour science community.

In step four, 'identify key drivers, facilitators and barriers', an online survey was conducted with UK 'makers'. Although the survey effectively and efficiently identified determinants of upcycling and target population (advantage), the outcomes heavily relied on the theoretical model, and the sample size and scope were limited (disadvantage). Further studies, with a broader population (e.g., UK citizens, citizens in other countries), would reveal potential commonalities and differences in key factors influencing upcycling and target populations based on demographics and geographical areas.

In step five, 'design promising interventions', synthesis of the research findings, idea generation and idea mapping with existing policy frameworks were carried out, resulting in 15 promising interventions (advantage). One limitation of the research was the idea generation and mapping exercise done by a single researcher (disadvantage). More breadth and depth might have been achieved if individual experts or stakeholders had been consulted in this design step. We recommend individual ideation and mapping by a group 
of people not as group brainstorming and group mapping due to the poor performance despite the illusion of group productivity [61].

In step six, 'evaluate and improve the draft interventions', a modified form of the Delphi approach was used. Asking experts to complete the questionnaire first and then having a workshop to further discuss the results was highly efficient and effective enough (advantage). However, the validity and reliability of the outcomes could be questioned in comparison with a traditional Delphi method (with a series of questionnaires) (disadvantage). Using a traditional Delphi method, despite being a more time-consuming process, could achieve greater validity and reliability for future studies. Since there will always be trade-offs between resources (e.g., time, budget) and the quality of outcomes, future researchers should assess their resources and capabilities before deciding on particular research methods.

Developing prototypes with actors, piloting and monitoring, evaluating pilot interventions, and feeding learning back into the design of promising interventions (i.e., the light grey textboxes in Figure 2) comprise the rest of the cycle in the adapted framework. The tasks of prototyping and piloting promising interventions are not for a short-term project by a single researcher; they demand a team of researchers, resources and support. Case studies to investigate interventions that have already taken place might serve as an alternative research avenue instead of prototyping and piloting the promising interventions. Sung [62], for example, evaluated two interventions for scaling-up upcycling, a community event in the UK and an upcycling plaza in South Korea. Such case studies can provide evidence in assessing the effectiveness of interventions, which could inform future intervention development and implementation by other relevant actors (e.g., government, local authorities, NGOs).

\section{Conclusions}

Recognising the knowledge gap in suggesting and evaluating particular general approaches to developing policy and design interventions in the area of design for behaviour change, this paper considered Darnton's Nine Principles framework as a potentially promising general approach and reviewed it critically, using the experience of its use in the case of research into scaling-up upcycling in the UK. Throughout the study, all three hypotheses turned out to be correct. When Darnton's Nine Principles framework was critically reviewed, the limitations were identified (H1). This is not surprising as many studies have reported on the limitations of varied conceptual frameworks [63-65]. When Darnton's Nine Principles framework was adapted, it was well applied to the case study (H2). This was also anticipated since the whole purpose of adaptation/modification was to make it better fit the case. As mentioned in the introduction, such framework modification is not unusual especially for behaviour interventions [66-68]. When the adapted Darnton's framework was applied to the case study, the results showed the usefulness of the adapted framework for policy and design intervention (H3) for the small-scale, exploratory study. Although the adapted framework's usefulness has been proven for this particular small-scale, exploratory study, what happens if we use it for a vastly different small-scale study or for a large-scale study? We do not have answers yet. This is for future studies. Overall, the study answered the key research question: 'Is Darnton's Nine Principles framework useful as a general approach to policy and design interventions'? The answer is probably yes, when adapted appropriately for the target behaviour and audience considering the unique circumstances in the case. Again, modification of a conceptual framework for better fit in a particular case study or tailoring the processes and fine details including interventions according to the unique circumstances in the case seems to be the key. This has been emphasised in existing studies on behaviour change interventions $[4,69,70]$.

This study is limited as the adapted framework was tested with only one case study. Potentially different case studies could yield different outcomes in terms of applicability and usefulness of the adapted framework (or the original framework). Future research could test the original and adapted frameworks with multiple case studies to evaluate 
whether the results reported in this paper can be generalised. Despite the limitation, this paper provides meaningful scientific and practical contributions as seen in Table 1 . We hope that our study will inform and inspire academic researchers and other actors in future studies and endeavours for behaviour change for the greater societal good.

Table 1. Scientific and practical contributions.

\section{Scientific Contribution}

\section{Practical Contribution}

- This study provided the first critical review of Darnton's Nine Principles framework as a potentially promising general approach to policy and design interventions

- The study extended our understanding of the Darnton's framework and its limitations, and how it can be adapted for small-scale, exploratory studies

- The study showed that Darnton's framework may not be suitable for the cases requiring new empirical research or having limited resources

- The study provided an upcycling case study in the UK demonstrating the use of an adapted Darnton's framework

- The study proved that the adapted framework may be suitable for use in small-scale, exploratory studies

- The study proved that the Darnton's Nine Principles framework may be a useful general approach to policy and design interventions, when adapted appropriately

- The study provided clear guidance, step-by-step processes and potential outcomes for future researchers and other relevant stakeholders to apply the adapted framework to other small-scale, exploratory studies

- The study offered detailed suggestions for future researchers to potentially improve their research activities and outcomes in terms of validity, reliability, effectiveness and efficiency

- The study showed the potential of different adaptation and use of Darnton's Nine Principles framework in other contexts and behaviour domains for policy and design interventions

Author Contributions: Conceptualization, K.S., T.C. and S.K.; methodology, K.S., T.C. and S.K.; data collection and analysis, K.S.; writing-original draft preparation, K.S.; writing—review and editing, K.S., T.C. and S.K.; supervision, T.C. and S.K.; funding acquisition, K.S. and T.C. All authors have read and agreed to the published version of the manuscript.

Funding: Conceptualisation, methodology development, data collection and analysis were funded by Nottingham Trent University and the Centre for Industrial Energy, Materials and Products, EPSRC (Engineering and Physical Sciences Research Council) grant number EP/N022645/1. Original draft preparation was funded by De Montfort University.

Institutional Review Board Statement: The study was conducted according to the guidelines of the Declaration of Helsinki, and approved by the Institutional Ethics Committee of Nottingham Trent University and De Montfort University.

Informed Consent Statement: Informed consent was obtained from all subjects involved in the study.

Data Availability Statement: The data presented in this study are openly available in DORA (De Montfort Open Research Archive) at [https:/ / doi.org/10.1007/978-3-319-47883-8_12 for the interview study; https://doi.org/10.3390/su11030870 for the online survey; https://doi.org/10.3390/en1 2142778 for the modified Delphi], all accessed on 30 December 2021.

Acknowledgments: This paper preparation and completion were possible with the generous staff innovation allowance from De Montfort University (DMU). We thank Guy Bingham, Stuart Lawson, Kelley Wilder, Siobhan Keenan and Deborah Cartmell for supporting this research at DMU.

Conflicts of Interest: The authors declare no conflict of interest. The funders had no role in the design of the study; in the collection, analyses, or interpretation of data; in the writing of the manuscript, or in the decision to publish the results.

\section{References}

1. Brown, T.; Wyatt, J. Design thinking for social innovation. Dev. Outreach 2010, 12, 29-43. [CrossRef]

2. $\quad$ Clune, S. Design and behaviour change. J. Des. Strateg. 2010, 4, 68-75.

3. Lilley, D. Designing for Behavioural Change: Reducing the Social Impacts of Product Use through Design. Ph.D. Thesis, Loughborough University, Loughborough, UK, 2005. 
4. Lockton, D.; Harrison, D.; Stanton, N. Making the user more efficient: Design for sustainable behaviour. Int. J. Sustain. Eng. 2008, 1,3-8. [CrossRef]

5. Niedderer, K. Mindful Design as a Driver for Social Behaviour Change. In Proceedings of the IASDR Conference, Tokyo, Japan, 26-30 August 2013.

6. McKenzie-Mohr, D.; Smith, W. Fostering Sustainable Behavior: An Introduction to Community-Based Social Marketing; New Society Publishers: Gabriola Island, BC, Canada, 1999.

7. Tang, T. Towards Sustainable Use: Design Behaviour Intervention to Reduce Household Environment Impact. Ph.D. Thesis, Loughborough University, Loughborough, UK, 2010.

8. Lockton, D.; Harrison, D.; Stanton, N.A. The Design with Intent Method: A design tool for influencing user behaviour. Appl. Ergon. 2010, 41, 382-392. [CrossRef]

9. Dorrestijn, S. The Product Impact Tool. In Design for Usability Methods E Tools: A Practitioner's Guide; van Kuijk, J., Staats, R., Eds.; IOP IPCR Design for Usability Research Project: Delft, The Netherlands, 2012; pp. 111-119.

10. Langer, E.J. Mindfulness; Da Capo Press: Boston, MA, USA, 2014.

11. Bason, C. Leading Public Sector Innovation: Co-Creating for a Better Society; Policy Press: Bristol, UK, 2010.

12. Bason, C. Design for Policy; Routledge: London, UK, 2014.

13. Boyer, B.; Cook, J.W.; Steinberg, M. Studio: Recipes for Systemic Change; Sitra: Helsinki, Finland, 2011.

14. European Commission. Design for Growth and Prosperity: Report and Recommendations of the European Design Leadership Board; European Design Innovation Initiative: Helsinki, Finland, 2012.

15. Darnton, A. Practical Guide: An Overview of Behaviour Change Models and Their Uses; Government Social Research Unit: London, UK, 2008.

16. Sung, K.; Cooper, T.; Kettley, S. An alternative approach to influencing behaviour: Adapting Darnton's Nine Principles framework for scaling up individual upcycling. In Proceedings of the DRS2016: Design + Research + Society-Future-Focused Thinking, Brighton, UK, 27-30 June 2016.

17. Stern, P. Toward a coherent theory of environmentally significant behavior. J. Soc. Iss. 2000, 56, 407-424. [CrossRef]

18. Sung, K.; Cooper, T.; Kettley, S. Individual Upcycling Practice: Exploring the Possible Determinants of Upcycling Based on a Literature Review. In Proceedings of the Sustainable Innovation 2014 Conference, Copenhagen, Denmark, 3-4 November 2014.

19. Sung, K. Sustainable Production and Consumption by Upcycling: Understanding and Scaling Up Niche Environmentally Significant Behaviour. Ph.D. Thesis, Nottingham Trent University, Nottingham, UK, 2017.

20. Stahel, W.R. The circular economy. Nature 2016, 531, 435-438. [CrossRef] [PubMed]

21. Ellen MacArthur Foundation. Circular Economy. Available online: http://www.ellenmacarthurfoundation.org (accessed on 27 December 2021).

22. Cooper, T. Longer Lasting Products; Routledge: Abingdon, UK, 2010.

23. Allwood, J.M.; Cullen, J.M.; Carruth, M.A.; Cooper, D.R.; McBrien, M.; Milford, R.L.; Moynihan, M.C.; Patel, A.C. Sustainable Materials: With Both Eyes Open; The Use Less Group: Cambridge, UK, 2012.

24. Sung, K.; Cooper, T. Sarah Turner-Eco-artist and designer through craft-based upcycling. Craft Res. 2015, 6, 113-122. [CrossRef]

25. Sung, K.; Cooper, T.; Ramanathan, U.; Singh, J. Challenges and support for scaling up upcycling businesses in the UK: Insights from small-business entrepreneurs. In Proceedings of the Product Lifetimes and the Environment Conference, Delft, The Netherlands, 8-10 November 2017.

26. Singh, J.; Sung, K.; Cooper, T.; West, K.; Mont, O. Challenges and opportunities for scaling up upcycling businesses-The case of textile and wood upcycling businesses in the UK. Resour. Conserv. Recycl. 2019, 150, 104439. [CrossRef]

27. Van den Bosch, S.J.M. Transition Experiments: Exploring Societal Changes Towards Sustainability. Ph.D. Thesis, Erasmus University Rotterdam, Rotterdam, The Netherlands, 2010.

28. Sung, K.; Cooper, T.; Kettley, S. Developing Interventions for Scaling Up UK Upcycling. Energies 2019, 12, 2778. [CrossRef]

29. CIE-MAP. About CIE-MAP. Available online: http:/ / ciemap.leeds.ac.uk/index.php/about/ (accessed on 27 December 2021).

30. EUED. End Use Energy Demand (EUED) Centres. Available online: http://www.eued.ac.uk/whatiseued (accessed on 27 December 2021).

31. UK Government. UK Becomes First Major Economy to Pass Net Zero Emissions Law. Available online: https://www.gov.uk/ government/news/uk-becomes-first-major-economy-to-pass-net-zero-emissions-law (accessed on 27 December 2021).

32. Triandis, H.C. Interpersonal Behavior; Brooks/Cole Publishing Company: Monterey, CA, USA, 1977.

33. Jackson, T. Motivating Sustainable Consumption: A Review of Evidence on Consumer Behaviour and Behavioural Change; University of Surrey: Guildford, UK, 2005.

34. Martiskainen, M. Affecting Consumer Behaviour on Energy Demand; University of Sussex: Brighton, UK, 2007.

35. Kallbekken, S.; Rise, J.; Westskog, H. Combining insights from economics and social psychology to explain environmentally significant consumption. In Sustainable Energy; Routledge: London, UK, 2010; pp. 127-145.

36. Sung, K.; Cooper, T.; Kettley, S. Factors Influencing Upcycling for UK Makers. Sustainability 2019, 11, 870. [CrossRef]

37. Sung, K.; Cooper, T.; Kettley, S. Individual Upcycling in the UK: Insights for Scaling up Towards Sustainable Development. In Sustainable Development Research at Universities in the United Kingdom; Springer: Cham, Switzerland, 2017; pp. 193-227.

38. Araújo-Soares, V.; Presseau, J. Theory-based behaviour prediction and change: An interview with Gaston Godin. Eur. Health Psychol. 2008, 10, 51-53. 
39. Gagnon, M.; Godin, G.; Gagné, C.; Fortin, J.; Lamothe, L.; Reinharz, D.; Cloutier, A. An adaptation of the theory of interpersonal behaviour to the study of telemedicine adoption by physicians. Int. J. Med. Inf. 2003, 71, 103-115. [CrossRef]

40. Bamberg, S.; Schmidt, P. Incentives, morality, or habit? Predicting students' car use for university routes with the models of Ajzen, Schwartz, and Triandis. Environ. Behav. 2003, 35, 264-285. [CrossRef]

41. Knoeri, C.; Russell, S. End-Users' Motivations and Barriers to Infrastructure Service-Performance Contracting: Survey Procedure and Design; University of Leeds: Leeds, UK, 2014.

42. Fishbein, M.; Ajzen, I. Belief, Attitude, Intention and Behavior: An Introduction to Theory and Research; Addison-Wesley: Reading, PA, USA, 1975.

43. Madden, T.J.; Ellen, P.S.; Ajzen, I. A comparison of the theory of planned behavior and the theory of reasoned action. Person. Soc. Psychol. Bull. 1992, 18, 3-9. [CrossRef]

44. Cohen, J.; Cohen, P.; West, S.G.; Aiken, L.S. Applied Multiple Regression/Correlation Analysis for the Behavioral Sciences; Routledge: New York, NY, USA, 2013.

45. Anderson, C. Makers: The New Industrial Revolution; Random House Business: London, UK, 2012.

46. Michie, S.; Abraham, C. Interventions to change health behaviours: Evidence-based or evidence-inspired? Psychol. Health 2004, 19, 29-49. [CrossRef]

47. Defra. Changing Behaviour through Policy Making; Department for Environment, Food \& Rural Affairs: London, UK, 2005.

48. Manzini, E.; Vezzoli, C. A strategic design approach to develop sustainable product service systems: Examples taken from the 'environmentally friendly innovation' Italian prize. J. Clean. Prod. 2003, 11, 851-857. [CrossRef]

49. Defra. A Framework for Pro-Environmental Behaviours; Department for Environment, Food \& Rural Affairs: London, UK, 2008.

50. Defra. The Sustainable Lifestyles Framework; Department for Environment, Food \& Rural Affairs: London, UK, 2011.

51. Michie, S.; van Stralen, M.M.; West, R. The behaviour change wheel: A new method for characterising and designing behaviour change interventions. Implement. Sci. 2011, 6, 42. [CrossRef] [PubMed]

52. Gagnon, M.; Sánchez, E.; Pons, J.M. From recommendation to action: Psychosocial factors influencing physician intention to use Health Technology Assessment (HTA) recommendations. Implement. Sci. 2006, 1, 5908-5901. [CrossRef] [PubMed]

53. Cotterill, S.; Stoker, L.R.G.; Wales, C. Reinvigorating the Civic: Searching for a Rationale for our Research Programme. In Proceedings of the Political Studies Association Conference 2008, Swansea, UK, 1-3 April 2008.

54. Salonen, A.O.; Helne, T.T. Vegetarian diets: A way towards a sustainable society. J. Sustain. Dev. 2012, 5, 10-24. [CrossRef]

55. Denscombe, M. Communities of practice a research paradigm for the mixed methods approach. J. Mix. Methods Res. 2008, 2, 270-283. [CrossRef]

56. Hammersley, M. Reading Ethnographic Research; Routledge: London, UK, 2016.

57. Al-Debei, M.M.; Al-Lozi, E.; Papazafeiropoulou, A. Why people keep coming back to Facebook: Explaining and predicting continuance participation from an extended theory of planned behaviour perspective. Decis. Support Syst. 2013, 55, 43-54. [CrossRef]

58. Baker, R.K.; White, K.M. Predicting adolescents' use of social networking sites from an extended theory of planned behaviour perspective. Comput. Hum. Behav. 2010, 26, 1591-1597. [CrossRef]

59. McMillan, B.; Higgins, A.R.; Conner, M. Using an extended theory of planned behaviour to understand smoking amongst schoolchildren. Addict. Res. Theory 2005, 13, 293-306. [CrossRef]

60. Donald, I.J.; Cooper, S.R.; Conchie, S.M. An extended theory of planned behaviour model of the psychological factors affecting commuters' transport mode use. J. Environ. Psychol. 2014, 40, 39-48. [CrossRef]

61. Pauhus, P.B.; Dzindolet, M.T.; Poletes, G.; Camacho, L.M. Perception of performance in group brainstorming: The illusion of group productivity. Person. Soc. Psychol. Bull. 1993, 19, 78-89. [CrossRef]

62. Sung, K. Evaluating two interventions for scaling up upcycling: Community event and upcycling plaza. In Proceedings of the 2020 International Conference on Resource Sustainability, Dublin, Ireland, 19-23 July 2021.

63. Birkett, S.; de Lange, K. Limitations of conventional models and a conceptual framework for a nutrient flow representation of energy utilization by animals. Br. J. Nutr. 2001, 86, 647-659. [CrossRef] [PubMed]

64. Weir, C.J. Limitations of the Common European Framework for developing comparable examinations and tests. Lang. Test. 2005, 22, 281-300. [CrossRef]

65. Horngren, C.T. Uses and limitations of a conceptual framework. J. Account. 1981, 151, 86.

66. Georgiadis, C.; Peris, T.S.; Comer, J.S. Implementing strategic flexibility in the delivery of youth mental health care: A tailoring framework for thoughtful clinical practice. Evid.-Based Pract. Child Adolesc. Ment. Health 2020, 5, 215-232. [CrossRef]

67. Lee, E. How Might Participation in Primary School Eco Clubs in England Contribute to Children's Developing Action-CompetenceAssociated Attributes? Ph.D. Thesis, University of Bath, Bath, UK, 2014.

68. Mjahed, L.B. Toward Sustainable Travel Behavior and Activity Engagement: Connected Users, Technology Engagement and Cohort Effects. Ph.D. Thesis, Northwestern University, Evanston, IL, USA, 2018.

69. Ryan, K. Tailoring EHealth Interventions for Weight Loss: An Integrative Person-Centred Approach. Ph.D. Thesis, University College Cork, Cork, Ireland, 2020.

70. Orji, R. Design for Behaviour Change: A Model-Driven Approach for Tailoring Persuasive Technologies. Ph.D. Thesis, University of Saskatchewan, Saskatoon, SK, Canada, 2014. 